\title{
ПІДВИЩЕННЯ РІВНЯ АВТОМАТИЗАЦІї БЛОКУ ОЧИЩЕННЯ УСТАНОВКИ РОЗДІЛЕННЯ ПОВІТРЯ
}

Increased automation of cleaning unit air separation unit П.П.Червоненко, к.т.н. ${ }^{1}$, В.А. Болтенков, к.т.н. ${ }^{2}$

\author{
${ }^{1,2}$ Одеський національний політехнічний університет, Одеса \\ ${ }^{1}$ E-mail: ppchervonenko@ukr.net \\ ${ }^{2}$ E-mail: vaboltenkov@ mail.ru
}

Copyright (C 2014 by author and the journal "Automation technological and business - processes". This work is licensed under the Creative Commons Attribution International License (CC BY). http://creativecommons.org/licenses/by/4.0/

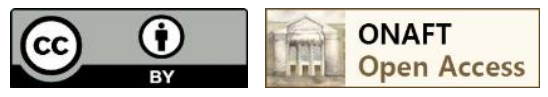

\begin{abstract}
Анотація
У статті розглянуто автоматизація блоку очищення установок розділення повітря середнього тиску, яким враховуючи сучасні вимоги ринку, необхідно підвищити рівень автоматизації. Проведено аналіз існуючих вимог до установок середнього тиску. Поставлена мета роботи - розробка інформаційної технології для підвищення рівня автоматизації блоку очищення установки розділення повітря. Для досягнення поставленої мети необхідно було проаналізувати технологічний процес блоку очищення. Обгрунтовано необхідність вибору дворівневої системи автоматизації. Нижній рівень являс локальну система управління і контролю, а верхній управляючий обчислювальний комплекс як робочу станцію на базі персонального комп'ютера. Розглянуто локальну систему управління та контролю, яка складається 3 блоку вимірювальних засобів, засобів регулювання та системи управління і контролю нижнього рівня. Приведено опис обладнання, що було використано для автоматизації блоку очищення. Розроблено програмне забезпечення робочої станції, що представлено графічним інтерфейсом користувача та управляючою програмою. Приведено опис алгоритмів керування блоком очищення, що підтримус роботу системи у трьох основних режимах, та дозволяс автоматично переходити між ними. Розробка і впровадження автоматичної системи управління роботою блоку очищення установки розділення повітря середнього тиску дозволило підвищити безпеку та ефективність роботи установки в цілому.
\end{abstract}

\section{Abstract}

У статті розглянуто автоматизація блоку очищення установок розділення повітря середнього тиску, яким враховуючи сучасні вимоги ринку, необхідо підвищити рівень автоматизації. Проведено аналіз існуючих вимог до установок середнього тиску. Поставлена мета роботи - розробка інформаційної технології для підвищення рівня автоматизації блоку очищення установки розділення повітря. Для досягнення поставленої мети необхідно було проаналізувати технологічний процес блоку очищення. Обгрунтовано необхідність вибору дворівневої системи автоматизації. Нижній рівень являє локальну система управління і контролю, а верхній управляючий обчислювальний комплекс як робочу станцію на базі персонального комп'ютера. Розглянуто локальну систему управління та контролю, яка складається 3 блоку вимірювальних засобів, засобів регулювання та системи управління і контролю нижнього рівня. Приведено опис обладнання, що було використано для автоматизації блоку очищення. Розроблено програмне забезпечення робочої станції, що представлено графічним інтерфейсом користувача та управляючою програмою. Приведено опис алгоритмів керування блоком очищення, що підтримує роботу системи у трьох основних режимах, та дозволяє автоматично переходити між ними. Розробка і впровадження автоматичної системи управління роботою блоку очищення установки розділення повітря середнього тиску дозволило підвищити безпеку та ефективність роботи установки в цілому. 
Ключові слова

Автоматизація блоку очищення, установка розділення повітря середнього тиску, управляючий обчислювальний комплекс, адсорбер.

Keywords

Automation unit cleaning, installation of air separation medium pressure, managing computer system, adsorber.

Постановка задачі в загальному вигляді та її актуальність

Атмосферне повітря є сировиною для здобуття таких промислових газів, як кисень, азот, аргон, неон, криптон, ксенон. Для виробництва промислових газів використовуються різні установки розділення повітря, серед яких значну частину складають установки середнього тиску наприклад «КжАж-045». Потреба в їх продукції надзвичайно висока в багатьох галузях промисловості.

Установки розділення повітря середнього тиску (УРПСТ) випускалися починаючи з 60-х років минулого століття. До 1995 р. було випущено близько 2000 установок, більшість з яких експлуатується на підприємствах колишнього СРСР до теперішнього часу. Значна частина працюючих установок $є$ морально і фізично застарілими та гостро потребують модернізації і автоматизації [1]. Модернізація може відбуватися за рахунок створення інформаційних технологій (IT) та є актуальною.

Аналіз існуючих рішень

При створенні IT необхідно враховувати сучасні вимоги ринку до установок розділення повітря середній продуктивності [2]. Головними вимогами $є$ :

- чистота продуктів. В установках розділення повітря, що забезпечують технологічні процеси, чистота продуктів (концентрації окремих газів) може відрізняться від стандартних. Тому при керуванні технологічним процесом у УРПСТ необхідно враховувати вимоги користувачів до чистоти продукції;

- багаторежимність, яка забезпечує експлуатацію УРПСТ в декількох режимах: газовому - 3 видачею газоподібних продуктів, рідинному - 3 видачею рідких продуктів та в змішаному - 3 видачею одночасно рідких і газоподібних продуктів;

- надійність і безпечність експлуатації. Забезпечується вдосконаленням технологічних схем, конструкцій апаратів і машин, вживання надійних матеріалів та процесів очищення від вибухонебезпечних домішок;

- забезпечення контролю і управління УРПСТ. В процесі експлуатації УРПСТ необхідно проводити моніторинг технологічного процесу, що вимагає знаходження компромісу між кількістю точок контролю та простотою схемних і конструктивних рішень.

УРПСТ складаються 3 наступних основних частин: устаткування для стиску атмосферного повітря, блок очищення, теплообмінні апарати для охолоджування повітря до кріогенних температур і нагріву продуктів розділення, колони ректифікації і конденсатори - випарники, кріогенні насоси [3]. Одним з найменш «автоматизованих» блоків в установках розділу повітря середнього тиску є блок очищення (БО), призначення якого - очищення повітря від пилу, двоокису вуглецю і вологи. Ретельне очищення від цих домішок - важлива умова забезпечення тривалості робочого періоду для всієї установки [6].

Мета роботи

Метою даної роботи є розробка IT для підвищення рівня автоматизації блоку очищення установки розділення повітря.

Викладення основного матеріалу дослідження

Опис технологічного процесу БО. Блок очищення (рис. 1, а) складається з двох адсорберів А20-А21 и А22-А23, один 3 адсорберів (наприклад, А20-А21) працює в режимі очищення повітря, в другому адсорбері (А22-А23) відбуваються послідовно процеси десорбції і охолодження адсорбенту [5]. У блоці очищення установки розділення повітря відбуваються складні хімічні і температурні процеси, які вимагають дотримання технологічних режимів експлуатації і управління. В існуючих УРПСТ контроль технологічних процесів, сигналізація про відхилення параметрів, блокування та захист технологічних агрегатів здійснюються за допомогою різних контрольно- 


\section{АВТОМАТИЧНІ ТА АВТОМАТИЗОВАНІ СИСТЕМИ УПРАВЛІННЯ ТЕХНОЛОГІЧНИМИ ПРОЦЕСАМИ}

вимірювальних приладів з функціями індикації та регістрації [4]. Людина-оператор здійснює керування виконавчими механізмами на основі контролю наступних показників:

1. температури (Т3 - температура повітря в блоці очищення; Т4 - температура повітря після блоку очищення Т13 - температура газу при регенерації; Т14 - температура газу, що регенерує;

2. тиску ( М9 - тиск газу в електропідігрівачі А14; M101 та М102- тиск в адсорберах);

3. витрат газу (Р1- витрата регенеруючого газу).

На базі контрольно-вимірювальної інформації забезпечується робота БО в трьох режимах [4]:

4. очищення повітря;

5. зміни режиму роботи адсорберів, що відбувалась згідно технологічного циклу по циклограмі через кожні 8 годин (незалежно від концентрацій домішок та стану адсорберу);

6. десорбції та охолодження.

Для проведення автоматизації БО проаналізовано особливості функціонування абсорберів, елементів контролю і управління.

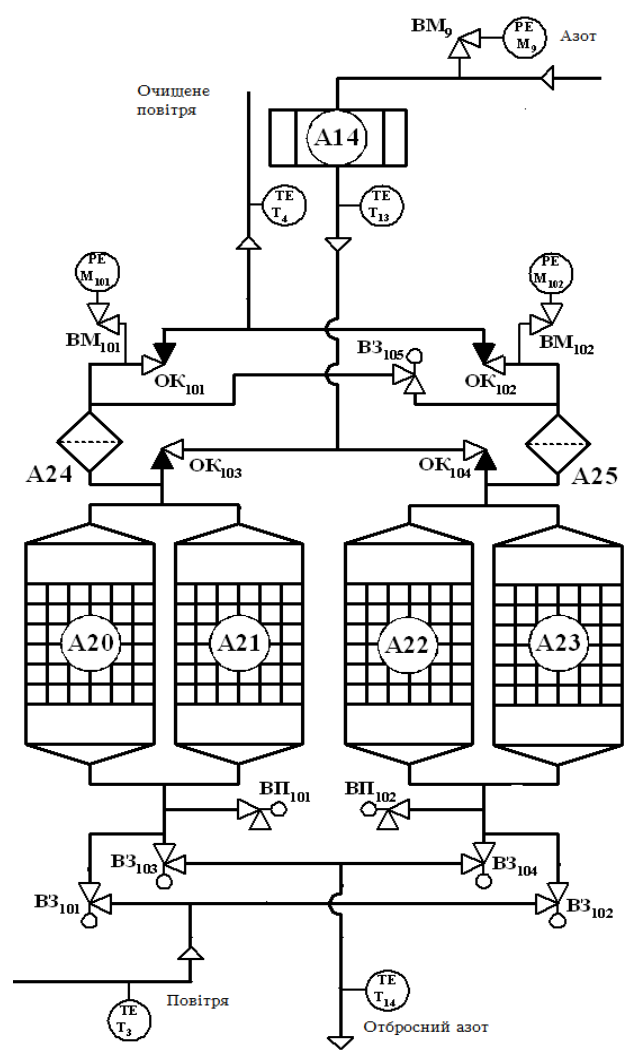

a)

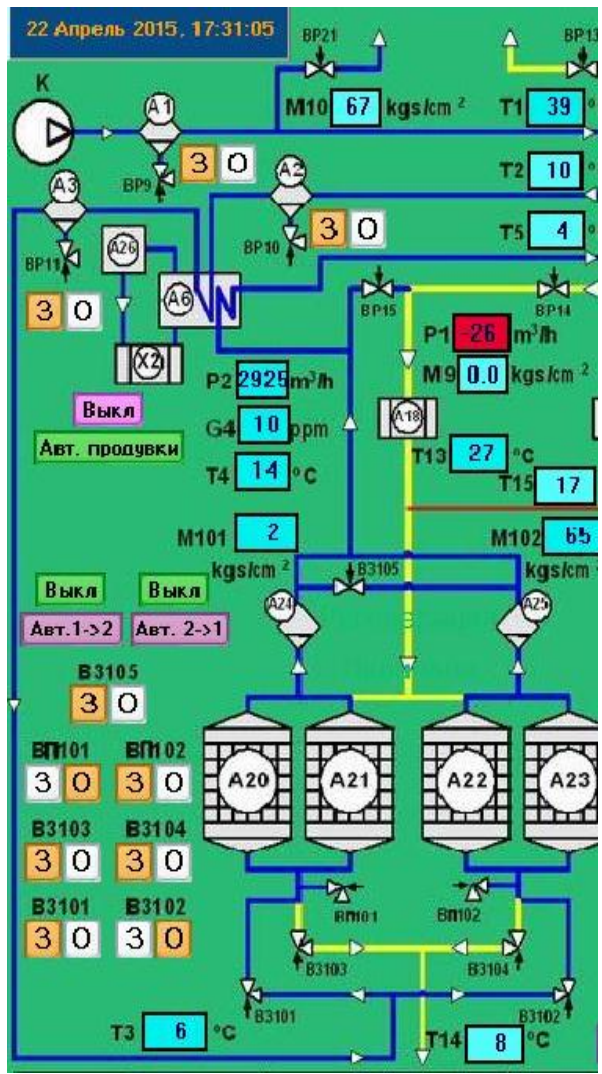

б)

Рис. 1 - Блок очищення УРПСТ а) - структурна схема блоку очищення; б) - фрагмент розробленого інтерфейсу користувача

Розроблена система автоматизації та контролю виконана як дворівнева. Нижній рівень являє локальну система управління і контролю, а верхній - управляючий обчислювальний комплекс як робочу станцію на базі персонального комп'ютера. Така організація дозволила розподілити функції контролю, управління та відображення інформації та підвищити безпеку технологічного процесу за рахунок його подвійного контролю.

Локальна система управління та контролю складається з блоку вимірювальних засобів, засобів регулювання та системи управління і контролю нижнього рівня.

Блок вимірювальних засобів включає датчики параметрів процесу, тобто вимірювальні перетворювачі тиску «КРТ5», витрат «Метран-350», температури «ТСП-100» та газоаналітичного контролю (ГАММА-100). зі 


\section{АВТОМАТИЧНІ ТА АВТОМАТИЗОВАНІ СИСТЕМИ УПРАВЛІННЯ ТЕХНОЛОГІЧНИМИ} ПРОЦЕСАМИ

стандартними вихідними сигналами. Застосування газоаналізатора дозволило контролювати стан адсорбера, та на основі цієї інформації приймати рішення про необхідність його регенерації, це дало можливість працювати не по циклограмі у 8 годин, як було раніше, а по циклограмі (залежно від показників газоаналітичного контролю) 15 - 19 годин. В результаті зменшення кількості регенерацій БО одержано значну економію витрат електроенергії.

Блок засобів регулювання включає електротехнічне обладнання, яке забезпечує виконання управляючих впливів та формування сигналів виконуючих пристроїв. У якості виконуючих пристроїв впроваджено електропневматичні клапани (В3105, В3104, В3103, В3102, ВП101, ВП102) виробництва фірми «Сатоzzі» (Італія). Клапани керуються електричним сигналом з силою струму $4 . .20$ мА і можуть знаходитись в положенні «відкрито» або «закрито» залежно від значення управляючого сигналу з контролеру.

При виборі вимірювальних засобів та виконавчих механізмів враховувались наступні вимоги: характеристика "ціна/якість", компактність, зручність монтажу, висока надійність та інш.

Система управління і контролю установкою нижнього рівня виконана на базі контролера фipми «WinCon». Даний контролер розроблено на базі процесора Intel Strong ARM 206 МГц. Контролер має вбудований відеоконтролер з портом VGA, роз'єми USB, PS/2 для маніпулятора і клавіатури, а також можливість підключення накопичувачів стандарту Compact Flash. Операційна система реального часу Windows CE.NET дозволяє програмувати «Wincon» користуючись сучасними технологіями проектування SCADA-систем та технологіями програмування Visual Basic.NET, Visual C\#, Embedded Visual C++ . Контролери «Wincon» мають промисловий модульний дизайн і виконані в корпусі з вбудованим блоком живлення, процесорним модулем і внутрішньою шиною до 7 слотів для підключення модулів з'єднання 3 об'єктами управління. Паралельна шина дозволяє встановити будь-які модулі (АЦП, ЦАП, ізольовані і неізольовані модулі дискретного вводу та виводу та інш.). Контролер «Wincon» забезпечує частотою опитування зовнішніх пристроїв від 10 Гц до 10 кГц. Великий набір комунікаційних інтерфейсів дозволяє створювати розподілені системи збору та обробки даних, організовувати зв'язок 3 іншими контролерами або віддаленими модулями по інтерфейсах RS-232, RS-485, Ethernet або USB. Перевагами даних контролерів є невисока ціна апаратних засобів, використання відкритих протоколів, що дозволяє інтегрувати в одну систему пристрої широкого спектру виробників, простота програмування та доступність широкого спектру програмного забезпечення, що мінімізує витрати часу і засобів на створення системи, простота інтеграції з системами управління більш високого рівня, що дозволяє спростити доступ до даних технологічних процесів з боку систем управління підприємством.

Управляючий обчислювальний комплекс виконано як робочу станцію на базі персонального комп'ютера.

Розроблене програмне забезпечення робочої станції представлено графічним інтерфейсом користувача та управляючою програмою.

Фрагмент розробленого інтерфейсу користувача наведено на рис. 1, б. Зручний інтерфейс користувача здійснює інформаційну підтримку процесу управління установкою розділення повітря. Інтерфейс являє систему візуалізації, що забезпечує детальне уявлення про стан окремих складових процесу, відображення графіків зміни технологічних параметрів, аварійних ситуацій, захисних блокувань, довідкову інформацію, контроль і реєстрація технологічних параметрів.

Інтерфейс користувача відображає наступну інформацію щодо блоку очищення установки розділення повітря:

7. функціональну схему (рис. 1, б);

8. х характер режиму роботи БО (ручне або автоматичне управління);

9. інформацію, яка отримана 3 датчиків параметрів процесу (синім кольором). Якщо отримані показники виходять за допустимі діапазони, колір відображення змінюється на червоний та вмикається звукова та світова сигналізація. Це дозволяє людині - оператору своєчасно реагувати та приймати відповідні рішення;

10. поточний стан управляючих механізмів(у вигляді прямокутників). Вони мають відповідне позначення та різний колір для двох станів «відкрито» або «закрито»;

- додаткову інформацію про зміну основних показників роботи БО у вигляді графічних залежностей їх значень від часу (передбачена можливість зміни тривалості зберігання та відображення інформації) .

Розроблений графічний інтерфейс дозволяє зосередити потрібну інформацію про технологічний процес, підвищити уважність людини-оператора, зменшити імовірність помилок та час простою.

Управляюча програма підтримує роботу системи у трьох основних режимах.

У режимі очищення повітря проводиться контроль за основними параметрами роботи та станом абсорбера, який працює у режимі очищення повітря. Основним показником для прийняття рішень на перехід у інший режим є значення на пристрої газоаналітичного контролю (Г4). Якщо цей показник перевищує допустиме значення, то на інтерфейс виводиться повідомлення «ПЕРЕХІД» про необхідність зміни режиму роботи адсорберів БО.

Зміна роботи адсорберів може проводитись як у ручному (за допомогою віртуальних кнопок управління на графічному інтерфейсі) так і у автоматичному режимі (вибір здійснюється шляхом натиснення на віртуальну кнопку «Авт.1->2»). 
В автоматичному режимі програма аналізує який адсорбер треба переключити. У випадку переходу з першого адсорбера на другий, електропневматичний клапан В3 104 закривається, та відкривається клапан В3 105, відбувається зрівняння тиску у адсорберах і при зрівнянні тисків у обох абсорберах (значення М102 дорівнює М101) відкривається клапан В3 102, та закриваються послідовно В3 105 та В3 101, та відкривається ВП 101. Відбувається скидання тиску у першому адсорбері. При досягненні тиску у першому абсорбері значення М101 $=3$ кг/см ${ }^{2}$ (необхідна умова: регулювання цього тиску від 1 до 7 кг/см ${ }^{2}$, з кроком в 1 кг/см ${ }^{2}$ ) відкривається клапан В3 103. Якщо виконується умова для витрат регенеруючого газу Р $1>250 \mathrm{~m}^{3}$ /год, то вмикається електропідігрівач А14.

У випадку переходу з другого абсорбера на перший електропневматичний клапан В3 103 закривається, та відкривається клапан В3 105, відбувається зрівняння тиску у адсорберах і при зрівнянні тисків у обох абсорберах (значення M102 дорівнює М101) відкривається клапан В3 101, та закриваються послідовно В3 105 та В3 102, та відкривається ВП 102. Відбувається скидання тиску у другому адсорбері. При досягненні тиску у другому абсорбері M101 $=3$ кг $/ \mathrm{cm}^{2}$ (необхідна умова: регулювання цього тиску від 1 до 7 кг $/ \mathrm{cm}^{2}$, 3 кроком в 1 кг/см ${ }^{2}$ ) відкривається клапан В3 104. Якщо виконується умова для витрат регенеруючого газу Р1 > $250 \mathrm{~m}^{3} /$ год, то вмикається електропідігрівач А14.

У режимі десорбції та охолодження програма здійснює десорбцію за рахунок керування електропідігрівачем А14, який автоматично підтримує температуру регенеруючого газу (азоту), що подається з електропідігрівача в блок очищення, у діапазоні $380-400^{\circ} \mathrm{C}$. Процес десорбції вважається закінченим, якщо на виході з адсорберу температура регенеруючого газу (T14) дорівнює $200^{\circ} \mathrm{C}$. У цьому випадку електропідігрівач відключається, на екрані монітору відображається напис «РЕГЕНЕРАЦІЮ ЗАКІНЧЕНО» та починається режим охолодження. У цьому режимі відбувається контроль температури Т14 та витрат регенерую чого газу Р1. При відповідних показниках приймається рішення про завершення режиму охолодження.

\section{Висновки}

Розробка і впровадження автоматичної системи управління роботою блоку очищення установки розділення повітря середнього тиску дозволило отримати економічний виграш від експлуатації даного вузла за рахунок зменшення енергоспоживання та витрат регенеруючого газу, зменшити час простою при виникненні аварійних ситуацій, виключити з процесу управління негативний вплив людського фактору. Це дало можливість підвищити безпеку та ефективність роботи установки в цілому.

\section{Література}

[1] А.В. Абрамов, В.В. Плотников, В.И. Рожинский Автоматизация воздухоразделительных установок. - М.: ЦИНТИхимнефтемаш, 1983.-38 с.;

[2] Ю.Д.Видинеев Автоматизация криогенных установок. - М.: Энергия, 1975. -192 с.;

[3] Н.В. Грязнов, А.И. Михайлушкин, А.И. Рохмистров Основы автоматизации производствынных процессов криогенной техники. - Л.: Машиностроение, 1980. - 181 с.;

[4] А.Д. Крючков Автоматизация установок разделения газов глубокого охлаждения. - Л.: Химия, 1970.-295с.;

[5] С.Я. Герш Эффективные циклы глубокого охлаждения и новые принципы разделения воздуха. - М.: Гос.научно-техн. изд-во машиностр. лит-ры, 1946. - 120 с.;

[6] В.И.Файнтейн Кислород, азот, аргон - безопасность при производстве и применении. - М.: Интермет Инжиниринг, 2008. - 198 с.

\section{References}

[1] A.V. Abramov, VV Plotnikov, V.I. Rozhen Automation of air separation plants. - M .: TsINTIhimneftemash, 1983.38 p.;

[2] Y.D. Vidineev automation of cryogenic installations. - M .: Energia, 1975. -192 p.;

[3] N.V. Grjaznov, A.I. Mikhailushkin, AI Rohmistrov proizvodstvynnyh Fundamentals of automation of processes of cryogenic equipment. - L .: Engineering, 1980. - 181 p.;

[4] A.D. Kryuchkov automation systems division deep cooling gases. - L .: Chemistry, 1970.-295s.;

[5] S.Y. Gersh Effective deep-freezing cycles, and new principles of air separation. - M .: Gos.nauchno-tehn. Publishing mechanical engineering. literature, 1946. - $120 \mathrm{p}$;

[6] V.I. Faynteyn Oxygen, nitrogen, argon - safety in production and use. - M .: Intermet Engineering, 2008. - 198 p. 